\title{
On the comparison of fisher information of some probability distributions
}

\section{ION MIHOC and CRISTINA-IOANA FĂTU}

\begin{abstract}
.
In 1998 Gupta, R. C., Gupta, P. L. and Gupta, R. D. have introduced the exponentiated exponential distribution (or the generalized exponential distribution) as a generalization of the standard exponential distribution. The mathematical properties of this distribution have been studied in detail by Gupta and Kundu (2001). The aim of this paper is to establish some relations concerning the Fisher's information of the generalized exponential distribution and the similar information corresponding in the case of the weighted version.
\end{abstract}

\section{REFERENCES}

[1] Gupta, R. C., Gupta, P. L. and Gupta, R. D. Modeling failure time data by Lehman alternative, Communication in Statistics-Theory and Methods, 27 (1998), 887-904

[2] Gupta, R. D. and Kundu, D. Exponentiated exponential family: an alternative to gamma and Weibull distributions, Biometrical Journal, 43 (2001), 117-130

[3] Mihoc, I. and Fatu, C. I. Comparison of the moments for the generalized exponential distributions. Paper presented at the International Conference of Sciences, 8-9 November 2013, Faculty of Science of the University of Oradea, Romania

[4] Patil, G. P. and Rao, C. R. Weighted distributions: a survey of their application. In P. R. Krishnaiah (Ed.), Applications of statistics, (1997), 383-405

[5] Schervish, M. J. Theory of statistics, John Wiley \& Sons, Inc., New York, London, 1963

Faculty of Mathematics AND COMPUter SCIENCE

"BABES-BOLYAI"UNIVERSITY OF CLUJ-NAPOCA

KOGALNICEABU 1, ROMANIA

E-mail address: imihoc@math.ubbcluj.ro

E-mail address: cristina.fatu@cantemircluj.ro

FACUlty of ECONOMics, CHRistian UniVERSITy "Dimitrie CANTEMIR"

T. Mihali 56, Cluj-Napoca, Romania

E-mail address: cristina.fatuecantemircluj.ro

Received: 30.10.2013; In revised form: 05.09.2014; Accepted: 20.10.2014

2010 Mathematics Subject Classification. 62B10, 62H10, 62J12.

Key words and phrases. Generalized exponential distribution, score function, Fisher information, weighted exponential distribution.

Corresponding author: Ion Mihoc; imihoc@math.ubbcluj.ro 